Revista Brasileira de Agricultura Irrigada v.13, nº.5, p. 3656 - 3661, 2019

ISSN 1982-7679 (On-line)

Fortaleza, CE, INOVAGRI - http://www.inovagri.org.br

DOI: $10.7127 /$ rbai.v13n5001127

Protocolo 1127.19 - 26/03/2020 Aprovado em 04/04/2020

\title{
PRODUÇÃO DE RÚCULA EM FUNÇÃO DA PROFUNDIDADE DO LENÇOL FREÁTICO
}

\author{
Camila Alves de Souza ${ }^{1}$; Beatriz de Abreu Araújo우 Talyson Weber Rodrigues Rolim¹; Márcia \\ Batista Torres ${ }^{1}$; Alexsandro Oliveira da Silva ${ }^{2}$
}

\begin{abstract}
RESUMO
Diante da tendência de aumento do consumo da cultura e a necessidade de informações sobre condições de umidade próxima ao sistema radicular da rúcula, a presente pesquisa teve por objetivo analisar os efeitos de diferentes profundidades do lençol freático na cultura da rúcula (Eruca sativa L.). $\mathrm{O}$ experimento foi realizado em lisímetros de drenagem com $3 \mathrm{~m}^{2}$ de área por $1,5 \mathrm{~m}$ de altura, possuindo um dreno para escoamento da água. $\mathrm{O}$ delineamento adotado foi em blocos casualizados com quatro tratamentos e quatro repetições. Os tratamentos utilizados foram as profundidades do lençol freático divididas em níveis (T1- $5 \mathrm{~cm}, \mathrm{~T} 2-15 \mathrm{~cm}, \mathrm{~T} 3-25 \mathrm{~cm}$ e T4- 30cm), mantidos através do monitoramento de piezômetros. Os seguintes parâmetros foram avaliados: altura da planta, comprimento da raiz, massa fresca da parte aérea, massa fresca da raiz, massa seca da parte aérea e raiz. Realizou-se a análise de variância, quando significativos pelo teste $\mathrm{F}$, realizou-se e teste de Tukey 5\% com as médias. O nível de lençol freático a uma profundidade de $25 \mathrm{~cm}$ apresentou os melhores resultados de rendimento de massa fresca da parte aérea e raiz, sendo indicado para utilização a fim de obter-se maior produção de rúcula.
\end{abstract}

Palavras-Chave: eruca sativa L., umidade do solo, drenagem.

\section{ARUGULA PRODUCTION IN FUNCTION OF THE DEPTH OF WATER TABLE}

\begin{abstract}
Given the growing trend of crop consumption and the need for information on humidity conditions near the arugula root system, this research aimed to analyze the effects of different depths of the water table on arugula (Eruca sativa L.) culture. The experiment was carried out in drainage lysimeters with $3 \mathrm{~m}^{2}$ in area by $1.5 \mathrm{~m}$ in height, with a drain to drain the water. The design was in randomized blocks with four treatments and four replications. The treatments used were the groundwater depths divided into levels $(\mathrm{T} 1-5 \mathrm{~cm}, \mathrm{~T} 2-15 \mathrm{~cm}, \mathrm{~T} 3-25 \mathrm{~cm}$ and T4-30cm). Plant height, root length, shoot fresh mass, root fresh mass, shoot dry mass and root dry mass were evaluated. With the data was performed the analysis of variance, when significant by the $\mathrm{F}$ test, was performed

\footnotetext{
${ }^{1}$ Discente do curso de Pós-graduação em Engenharia Agrícola da Universidade Federal do Ceará, Fortaleza, Ceará Email: camilaifce2014@gmail.com; beatrizdeabreuaraujo@gmail.com; talysinw@gmail.com; marciabtagro@gmail.com ${ }^{2}$ Docente do do curso de Pós-graduação em Engenharia Agrícola da Universidade Federal do Ceará, Fortaleza, Ceará. Email:alexsandro@ufc.br
} 
and Tukey test $5 \%$ with the means. The groundwater level at a depth of $25 \mathrm{~cm}$ presented the best results of fresh mass yield of the shoot and root, being indicated for use in order to obtain greater arugula production.

Keywords: eruca sativa L., soil moisture, drainage.

\section{INTRODUÇÃO}

A rúcula (Eruca sativa L.) é uma hortaliça folhosa herbácea pertencente à família das Brassicaceae originária do sul da Europa e da parte ocidental da Ásia, de crescimento vegetativo rápido e ciclo curto, $\mathrm{e}$ produz folhas ricas em vitaminas $\mathrm{A}, \mathrm{C}$ e sais minerais, principalmente cálcio e ferro (DIJKSTRA et al., 2017).

No Brasil é uma cultura bastante conhecida nos Estados do Sul e Sudeste, principalmente entre os descendentes de italianos, espanhóis e portugueses, além dessas regiões, a rúcula já vem sendo cultivada e consumida em todas as regiões do país (PURQUERIO et al., 2007; STEINER et al., 2011). O aumento do consumo se deu devido principalmente ao sabor picante presente nas folhas e ainda por possuir nutrientes minerais importantes componentes benéficos (D'ANTUONO et al., 2009).

Apesar de ser uma cultura que se adaptada à condição de clima mais ameno, existem na região Nordeste do Brasil pequenas áreas com essa folhosa, que ficam localizadas próximo aos centros consumidores. A condução de cultivo e seu ciclo são parecidos aos de espécies como alface e coentro, hortaliças que são bastante cultivadas nessa região (GRANGEIRO et al., 2011; PURQUERIO et al., 2007).

No campo agronômico poucas hortaliças são ambientadas a mudanças extremas de temperatura e umidade, a exemplo de inundações temporárias e contínuas sendo provocadas por irrigações excessivas ou precipitações, presença de camadas superficiais compactadas e inundações ou até mesmo pela proximidade do nível do lençol freático (TOMASSONI et al., 2013). O excesso de umidade no solo acarreta uma deficiência de oxigenação, pois a água ocupa os locais dos poros, assim levando a uma redução da produção da cultura, sendo que a sensibilidade das culturas ao excesso de umidade é dependente do clima e do estágio fenológico em que a inundação acontece (CARPISKI et al., 2013a).

Segundo Carpiski et al. (2013b) a sub irrigação por meio de controle da profundidade do lençol freático pode suprir a falta de água às plantas e implicações com déficit hídrico e também pode ser um método importante, garantindo uma maior produtividade e reduzindo o estresse nas plantas.

Diante da tendência de aumento do consumo da cultura e a necessidade de informações sobre condições de umidade próximo ao sistema radicular da rúcula, a presente pesquisa teve por objetivo analisar os efeitos de diferentes profundidades do lençol freático na cultura da rúcula (Eruca sativa L.).

\section{MATERIAL E MÉTODOS}

O experimento foi realizado na área experimental do Laboratório de Hidráulica e Irrigação do Departamento de Engenharia Agrícola da Universidade Federal do Ceará, Campus - Pici, localizada no município de Fortaleza - CE, com coordenadas de $3^{\circ} 44^{\prime}$ $38,6^{\prime \prime}$ sul e $38^{\circ} 34^{\prime} 54,5^{\prime \prime}$ oeste, e altitude de $19 \mathrm{~m}$.

O clima da região é do tipo Aw', segundo a classificação de Köppen, com precipitação média anual de $1350 \mathrm{~mm}$ concentrada nos meses de janeiro a abril; a temperatura média anual é de $26,5^{\circ} \mathrm{C}$, com média mínima de $23^{\circ} \mathrm{C}$ e máxima de $29,3^{\circ} \mathrm{C}$, insolação de 2870 horas anuais e umidade relativa do ar de $80 \%$.

Os lisímetros foram dotados de um sistema de drenagem interna e abastecimento de água individual, por meio de um reservatório elevado situado ao lado dos 
mesmos, contendo um sistema de registros para regular a altura máxima da água no reservatório. A altura do nível freático foi controlada através de monitoramento realizado através de piezômetros em cada tratamento durante todo o ciclo. A área experimental tinha dimensões de $2 \mathrm{~m} \times 1,5 \mathrm{~m}\left(3 \mathrm{~m}^{2}\right)$, o solo presente no interior dos lisimetros era constituído em sua maioria por areia (cerca de 95\%).

O delineamento experimental utilizado foi de blocos casualizados com quatro tratamentos e quatro repetições, totalizando 16 unidades experimentais. Os tratamentos utilizados foram compostos de quatro profundidades de lençol freático $(\mathrm{T} 1=5 \mathrm{~cm}$;

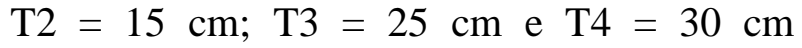
equivalente a ausência de lençol freático).

A cultura utilizada foi à rúcula (Eruca Sativa L.), variedade (Cultivada). A semeadura foi feita em bandejas de polietileno com 200 células. Quando as plantas apresentaram duas folhas definitivas realizouse o transplante das mudas para os tanques, ocorrido dia 26 de abril de 2018 segundo recomendações de Trani e Raij (1996). Cada parcela continha seis plantas, com aproximadamente $13 \mathrm{~cm}^{2}$ de área para cada planta. $\mathrm{O}$ experimento teve duração de 30 dias após o transplante das mudas, compreendendo assim o ciclo da cultura.

Avaliou-se a altura da planta (AP) e comprimento de raiz (CR) medidos com auxílio de uma trena, graduada em $\mathrm{cm}$; a massa fresca da parte aérea (MFPA), massa fresca da raiz (MFR), massa seca da parte aérea (MSPA) e massa seca da raiz (MSR), sendo os pesos determinadas em balança de precisão de 0,01g; A MSPA e MSR foram obtidas após secagem em estufa com temperatura de $65^{\circ} \mathrm{C}$ sendo pesadas também em balança analítica com precisão de $0,01 \mathrm{~g}$.

Com os dados obtidos realizou-se a análise de variância e a comparação de médias pelo teste de Tukey a 5\% de probabilidade utilizando o programa estatístico ASSISTAT 7.7 beta. A exposição dos dados foi feita por meio de Tabela e Gráficos.

\section{RESULTADOS E DISCUSSÃO}

A produção de massa fresca da parte aérea (MFPA) e massa seca da raiz (MSPA) foram as únicas variáveis a apresentarem diferenças significativas entre os tratamentos utilizados (níveis de lençol freático). As demais variáveis de crescimento (AP, CR, MFR e MSR) não mostraram nenhum efeito advindo dos níveis de lençol freático, o que remete dizer que mesmo em condições de níveis de lençol freático bem próximo ao sistema radicular (condição de excesso de umidade do solo) as plantas não foram influenciadas significativamente pelos tratamentos (Tabela 1).

Tabela 1. Resumo da análise de variância das variáveis de crescimento e produção da rúcula submetida a diferentes níveis do lençol freático.

\begin{tabular}{lccccccc}
\hline \multicolumn{1}{c}{ Fontes de variação } & GL & AP & CR & MFPA & MFR & MSPA & MSR \\
\hline Tratamentos & 3 & $30,944^{\mathrm{ns}}$ & $0,14262^{\mathrm{ns}}$ & $19,084^{*}$ & $0,704^{\mathrm{ns}}$ & $4,769^{*}$ & $0,162^{\mathrm{ns}}$ \\
Resíduo & 12 & 9,192 & 0,313 & 2,901 & 0,306 & 0,917 & 0,150 \\
Total & 15 & 203,137 & 4,178 & 92 & 6 & 25 & 2,290 \\
\hline CV \% & & 14,14 & 12,04 & 24,96 & 27,75 & 29,85 & 33,55
\end{tabular}

*,**: significativo a 5 e $1 \%$ de probabilidade, respectivamente, pelo teste $\mathrm{F}$; ns: não significativo; médias seguidas pela mesma letra não diferem estatisticamente na mesma coluna pelo teste de Tukey $(\mathrm{p}<0,05)$. 
A análise de crescimento é a referência inicial na análise de produção das plantas, demandando informações que podem ser obtidas sem a necessidade de equipamentos sofisticados (PEREIRA; MACHADO, 1987).

Carpiski et al. (2013b), estudando a sensibilidade da alface americana sob diferentes profundidades de lençol freático também tiveram resultados em que a altura da planta não foi influenciada pelos diferentes níveis freáticos. Tomassoni et al. (2013), avaliando o desenvolvimento da couve-flor submetido a diferentes níveis de lençol freático observaram que a massa fresca e seca da raiz não foram influenciadas pelos níveis

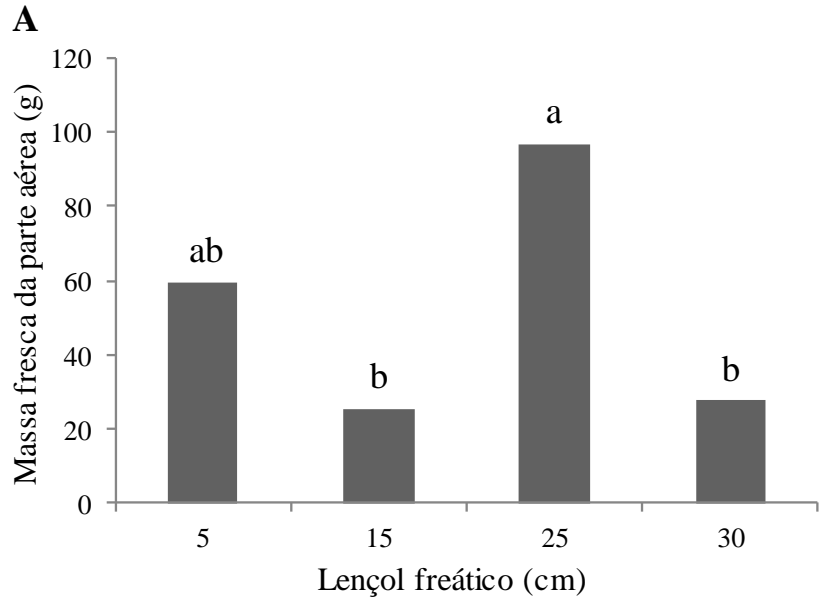

freáticos. As plantas apresentaram melhor rendimento de massa fresca e seca da parte aérea quando submetidas à profundidade do lençol freático equivalente a $25 \mathrm{~cm}$, evidenciando que a cultura possui uma maior preferência para absorção de água quando o nível freático esta abaixo do sistema radicular.

A partir de $25 \mathrm{~cm}$ de profundidade o rendimento da cultura apresentou uma queda de aproximadamente $70 \%$ (no nível de profundidade de $30 \mathrm{~cm}$ ), o que evidencia uma certa exigência da cultura a condições de umidade mais próximas ao sistema radicular (Figura 1).

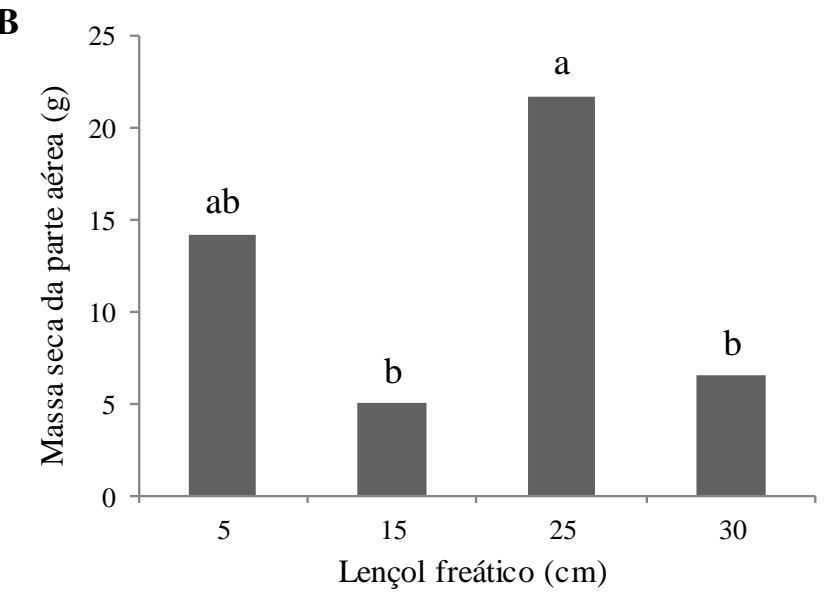

Figura 1. Massa fresca da parte aérea (A) e massa seca da parte aérea (B) de plantas de rúcula submetidas a níveis de profundidade de lençol freático $(5 ; 15 ; 25$ e $30 \mathrm{~cm})$.

A massa fresca e seca da parte aérea da cultivar 'cultivada', na melhor condição para as plantas de profundidade de lençol freático foi de 97 e $22 \mathrm{~g}$, respectivamente.

Resultados esses que ficaram acima dos encontrados por ROSSI et al. (2004) que observaram que a produção de massa fresca da parte aérea e da raiz da rúcula cultivar 'cultivada' foi de aproximadamente 81 e $5 \mathrm{~g}$, respectivamente. Assim como para a massa seca da parte aérea e da raiz ficaram em torno de 3 e $0,41 \mathrm{~g}$, respetivamente no presente estudo.

Trabalhando com a cultura do rabanete, Carmichael et al. (2012) e Almeida et al. (2018) observaram que a medida em que havia uma maior disponibilidade de água no solo para as plantas, proporcionava um aumento na produção da parte aérea da cultura. Segundo Carvalho et al. (2012) o sistema radicular da rúcula é superficial, o que torna a cultura exigente para a irrigação suplementar; além disso a cultura também é muito sensível ao déficit hídrico do solo, tornando assim a irrigação uma prática indispensável para que a hortaliça consiga atingir bons níveis de produção em condições de baixa disponibilidade pluviométrica. Em um estudo realizado por Araújo et al. (2018), avaliando diferentes níveis de água aplicados na cultura da rúcula foi constatado pelos autores que as plantas apresentaram melhores resultados de crescimento quando a quantidade de água aplicada era suficiente para suprir a necessidade hídrica total da cultura, evidenciando assim que em condições de 
estresse hídrico o crescimento das plantas é comprometido.

A ausência de efeito significativo dos tratamentos nas demais variáveis de crescimento pode ter tido influência da proximidade entre os níveis de profundidade do lençol freático avaliados e as raízes das plantas. Além do que o sistema radicular da rúcula ficou em torno de $22 \mathrm{~cm}$ de profundidade, o que corresponde ao intervalo dos níveis avaliados e também remete dizer que o sistema radicular da rúcula é atuante em quase todo o seu comprimento total, ou seja, há a presença de raízes absorventes em todo o comprimento radicular e não só até uma determinada profundidade do sistema radicular.

Os resultados encontrados por Carpiski et al. (2013a) na cultura crambe, da mesma família da rúcula, divergem aos encontrados nesse trabalho, onde observaram que a altura da planta foi influenciada de forma crescente em função das profundidades do lençol freático e que o rebaixamento em relação a superfície do solo proporcionou uma maior altura da planta.

\section{CONCLUSÕES}

A partir dos resultados obtidos na presente pesquisa pode ser concluído que a profundidade de lençol freático de $25 \mathrm{~cm}$ apresentou-se como ideal para um melhor rendimento de folhas de rúcula, sendo indicado como condição ótima de umidade para a cultura.

\section{REFERÊNCIAS BIBLIOGRÁFICAS}

ALMEIDA, A. V. R.; ARAGÃO, M. F.; SOUSA, H. G.; BEZERRA, F. M. S.; SILVA, A. O. Influência de níveis freáticos nos parâmetros produtivos e fisiológicos da cultura do rabanete. Revista Brasileira de Agricultura Irrigada, v.12, n.5, p.29072922, 2018. https://doi.org/10.7127/rbai.v12n500866.
ARAÚJO, B. A.; DEMONTIÊZO, F.. L. L.; ARAÚJO, D.A. SILVA, E.S.; VALNIR JÚNIOR, M. MOREIRA, F. J. C. Desenvolvimento de Eruca Sativa L. sob diferentes lâminas de irrigação e substratos.

Revista Brasileira de Agricultura Irrigada, v. 12, n. 4, (edição especial) p. 2731-2739, 2018.

https://doi.org/10.7127/rbai.v12n400964.

CARPISKI, M.; SANTOS, R. F.; PRIMIERI, C.; Silveira, L.; BASSEGIO, D.; TOMASSONI, F.; NAKAI, E. H. Sensibilidade do crambe (Crambe abyssinica) a variação de nível de lençol freático. Acta Iguazu, v. 2, n. 4, p. 36-45, 2013 a.

CARPINSKI, M.; SANTOS, R. F.; ROSA, H. A.; BASSEGIO, D.; SILVEIRA, L.; TOMASSONI, F. Sensibilidade da alface americana (Lactuca sativa) sob nível freático. Acta Iguazu, v. 2, n. 4, p. 55-64, $2013 b$.

CARVALHO, K. S.; BONFIM-SILVA, E. M.; SILVEIRA, M. H. D.; CABRAL, C. E. A.; LEITE, N. Rúcula submetida à adubação nitrogenada via fertirrigação. Revista Enciclopédia Biosfera, v. 8, p.1545-1553, 2012.

CARMICHAEL, P. C.; SHONGWE, V. D.; MASARIRAMBI, M. T.; MANYATSI, A. M. Effect of mulch and irrigation on growth, yield and quality of radish (Raphanus sativus L.) in a semi-arid sub-tropical environment. Asian Journal of Agricultural Sciences, v. 4, n. 3, p. 183-187, 2012.

D'ANTUONO, L.F.; ELEMENTI, S.; NERI, R. Exploring new potential health-promoting vegetables: glucosinolates and sensory attributes of rocket salads and related Diplotaxis and Eruca species. Journal of the Science of Food and Agriculture, v.89, p.713-722, 2009.

DIJKSTRA， D. D.; LONGO, U.; GUILHERME, I. H.; FERREIRA, R. V.; DIAS, L. N. S.; BUSO, W. H. D. Cultivo de 
Eruca sativa sob diferentes manejos nutricionais. Agrarian, v. 10, n. 35, p. 61-69, 2017.

GRANGEIRO, L. C.; FREITAS, F. C. L.; NEGREIROS, M. Z.; MARROCOS, S. T. P.; LUCENA, R. R.; OLIVEIRA, R. A. Crescimento e acúmulo de nutrientes em coentro e rúcula. Revista Brasileira de Ciências Agrárias, v.6, n.1, p. 11-16, 2011. https://doi.org/10.5039/agraria.v6i1a634.

PEREIRA, A. R.; MACHADO, E. C. Análise quantitativa do crescimento de comunidades vegetais. Campinas, SP: Instituto Agronômico. 1987. 33p. (IAC Boletim técnico $\mathrm{n}^{\circ} 114$ ).

PURQUERIO, L. F. V.; DEMANT, L. A. R.; GOTO, R.; BOAS, R. L. V. Efeito da adubação nitrogenada de cobertura e do espaçamento sobre a produção de rúcula. Horticultura Brasileira, v.25, n.3, p.464-470, 2007.

ROSSI, F.; FABRI E. G, SALA, F.C.;
RONDINO, E.; MINAMI, K. MELO, P. C. T. DE; COSTA, C. P. DA. Caracterização varietal de rúcula (Eruca sativa) cultivada. Horticultura Brasileira. V. 22 n. 2, p.391, 2004.

STEINER, F.; PIVETTA, L. A.; CASTOLDI, G.; PIVETTA, L. G.; FIOREZE, S. Produção de rúcula e acúmulo de nitrato em função da adubação nitrogenada. Revista Brasileira de Ciências Agrárias, v.6, n.2, p.230-235, 2011. https://doi.org/10.5039/agraria.v6i2a950.

TOMASSONI, F.; SANTOS, R. F.; Rocha, A. A.; GALDINO, T. S.; NADALETI, W. C.; ROSSI, E.; CARPINSKI, M. Sensibilidade da couve-flor ao excesso de água no solo. Acta Iguazu, v. 2, n. 4, p. 1-6, 2013.

TRANI, P. E.; RAIJ. B. Van. Hortaliças. In: RAIJ, B.Van.; CANTARELLA, H.; QUAGGIO, J. A.; FURLANI, A.M.C. Recomendações de adubação e calagem para o estado de São Paulo. 2. ed. Campinas: IAC, p.157-186, 1996. (Boletim técnico, n. 100). 